\title{
The Quality of Forensic Child Interviewing in Child Sexual Abuse Cases in Indonesia
}

\author{
Nathanael E. J. Sumampouw ${ }^{1,2}$ (D) $\cdot$ Henry Otgaar ${ }^{1,3} \cdot$ David La Rooy $^{4} \cdot$ Corine de Ruiter $^{1}$ \\ Published online: 9 August 2019 \\ (C) The Author(s) 2019
}

\begin{abstract}
Most of the foregoing research on child investigative interviewing has focused on interview practices in Western countries, thus potentially limiting the generalizability and application of the findings to improve interview practices in non-Western countries. The current studies are the first to examine police interviewing practices involving alleged child sexual abuse (CSA) victims in Indonesia which has marked cultural differences compared with Western countries. In Study 1, we presented Indonesian police child interviewers $(N=26)$ with a sexual abuse case vignette concerning a 7-year-old girl. Police interviewers were asked to write down the questions they would pose to the child. We categorized questions into four types: open-prompts, directives, optionposing, and suggestive. In Study 2, we examined Indonesian police files $(N=24)$ containing child sexual abuse interviews and also scored the type of questions used as per the first study. We compared our data with those obtained in Western countries. The consistent finding in both studies is that Indonesian police interviewers rarely used open-prompts, asked more directive and option-posing questions. Consistent with findings from Western countries, our studies provide indirect evidence that openprompts may be infrequently used by forensic child interviewers in Indonesia.
\end{abstract}

Keywords Children $\cdot$ Child sexual abuse $\cdot$ Memory $\cdot$ Forensic interview $\cdot$ NICHD protocol

\section{Introduction}

Child sexual abuse (CSA) is a public health problem with a global prevalence estimated at $11.8 \%$, or 118 per 1000 children (Stoltenborgh et al. 2011). CSA violates the UN Convention of the Rights of the Child aiming to protect the child from all forms of sexual exploitation and sexual abuse (UNICEF 2004, p. 10). CSA has serious social, psychological, and physical health consequences (Widom and Massey 2015), oftentimes with a life-long devastating impact (Borg et al. 2014; Daray et al. 2016).

Despite its serious impact, the prosecution of CSA cases is often complicated because legal cases often hinge solely on

Nathanael E. J. Sumampouw

nael.sumampouw@maastrichtuniversity.nl

1 Faculty of Psychology and Neuroscience, Forensic Psychology Section, Maastricht University, P.O. Box 616, 6200

MD Maastricht, The Netherlands

2 Universitas Indonesia, Depok, Indonesia

3 Catholic University Leuven, Leuven, Belgium

4 Royal Holloway University of London, London, UK the testimony of a child victim. Often, no objective forensic evidence (e.g., photographs, physical traces) is available and triers of fact have to base legal decision-making on what a child victim remembers about the abusive event(s) (Cross et al. 1994; Cross and Whitcomb 2017; Herman and Freitas 2010; Otgaar et al. 2017). In addition, many alleged CSA victims are reluctant to report abuse when interviewed in a forensic context, even when there is clear and objective evidence of abuse (Hershkowitz et al. 2014). Other relevant issues are the suggestibility and the tendency to acquiesce to authoritative figures of children (Bruck and Ceci 1999) which call for specific precautions in forensic interviews. Because of these issues (lack of disclosure, lack of objective evidence, and suggestibility), interviewing alleged CSA victims, notably younger children, is a challenging but highly important task (Hershkowitz et al. 1998; Lamb et al. 2000; Lamb et al. 2003).

Specialized skills are required when interviewing children in a forensic context (e.g., using open-prompts that enable children to provide a free narrative using minimal specific questions; Powell et al. 2010). However, forensic interviewers frequently lack basic knowledge and training about how to appropriately interview children (Poole 2016; Powell et al. 2010; Wood and Garven 2000). The core recommendations for interviewing children are derived from basic principles of 
memory retrieval and social influence, for example: eliciting freely recalled narratives, following the child as witness' train of thoughts, and avoiding suggestive questions (Poole 2016).

A substantial body of research has resulted in improvements in forensic child interviews (Lamb et al. 2008; Perona et al. 2005; Poole 2016). Open-prompts (e.g., "Tell me what happened?") have repeatedly been shown to elicit more accurate and less contaminated information than focused questions (e.g., "What did he wear?") (Hershkowitz 2001; Lamb et al. 2008). Furthermore, responses to open-prompts are at least three to five times more informative in terms of eliciting forensically relevant details than responses to more focused questions (Lamb et al. 2008; Poole 2016; Sternberg et al. 2001a, 2001b; Sternberg et al. 1996).

\section{Child Investigative Interviewing}

Experts in the field of child interviewing developed childfriendly interview protocols integrating findings from controlled laboratory experiments and field-based research to assist interviewers in obtaining accurate statements (Lamb et al. 2008; La Rooy et al. 2015). A clear advantage of using a standard protocol is to promote a practical procedure that employs a coordinated and interdisciplinary approach which might reduce the number of child interviews, avoid distress in children and improve the quality of children's testimonies (Cheung and Boutte-Queen 2010). Some examples of protocols are the cognitive interview (Fisher and Geiselman 1992), the memorandum of good practice (Davies and Westcott 1999), the step-wise interview (Yuille et al. 1993), the Ten Step investigative interview (Lyon 2005) and the National Institute of Child Health and Development (NICHD) interview protocol (Lamb et al. 2008).

These interview protocols, except the Cognitive Interview, were specifically designed for use with children. They highlight the importance of creating a child-friendly investigative setting. Conversational practices with a child can be used to achieve various goals, such as to enhance retrieval and accurate reporting of information about experienced events (Lamb et al. 2008), to maximize the amount and quality of the information while minimizing contamination of that information, and to minimize the impact of the investigation on the child (Yuille et al. 2009).

The abovementioned protocols have several components in common, as they are structured and guide interviewers through a set of interview phases. For example, a general structure was proposed in the Memorandum of Good Practices by using rapport building, asking for a free narrative and focusing on openended questions (Davies and Westcott 1999). Although many child interview protocols are similarly structured, the NICHD interview protocol is the most widely researched forensic child interview protocol (Benia et al. 2015). For this reason, we have used certain principles of the NICHD Protocol (i.e., coding of different types of questions) in the current studies.

The NICHD protocol is an evidence-based protocol for interviewing alleged CSA victims (Benia et al. 2015). The NICHD Protocol has been shown to elicit detailed (Cyr and Lamb 2009; Lamb et al. 2003) and accurate (Otgaar et al. 2018a, 2018b) information from children. The NICHD Protocol incorporates scientific knowledge on the developmental capabilities of children (e.g., memory functioning, disclosure of abuse) and creates conditions for maximizing children's productivity and the likelihood of accurate statements regarding experiences of abuse (Ahern et al. 2015; La Rooy et al. 2015). The NICHD Protocol provides interviewers with a clear structure, guiding them through each phase of the interview, and helping them to avoid poor questioning strategies that might lead to contamination or memory distortions (Lamb et al. 2007). The main focus of the NICHD Protocol is to guide interviewers towards using open-prompts that have been found to encourage children to provide more accurate testimonies than when other types of questions are used. Furthermore, the NICHD Protocol stresses that other types of specific and/ or focused questions (e.g., "Where did you meet the man?"), option-posing: "Did he wear a black or blue coat?") should be used only when free recall is exhausted in response to openprompts. These focused questions should be used in tandem again with open-prompts. Another important feature of the NICHD Protocol is that it starts with a rapport-building phase, narrative and episodic memory training, both of which facilitate episodic memory retrieval (Saywitz et al. 2015).

Recent findings on CSA forensic interviews reveal that the use of the NICHD Protocol increases the likelihood that alleged victims make accurate allegations of abuse, including cases of intra-familial abuse (Ahern et al. 2014; Hershkowitz et al. 2014; La Rooy et al. 2015). Moreover, Pipe et al. (2013) demonstrated that protocol interviews were more likely to yield charges filed and guilty verdicts than non-protocol interviews (but see also Pichler et al. 2019). Furthermore, Gagnon and Cyr (2017) examined preschool children, aged 3 to 5 years old who disclosed an episode of sexual abuse. They analyzed the NICHD Protocol transcripts and found that these transcripts contained more details when open-prompts were used compared to specific and/or focused questions. However, the NICHD Protocol by itself does not ensure interview quality. Ongoing feedback about how interviews are conducted is a crucial necessity of the NICHD Protocol interview training (Lamb et al. 2002; La Rooy et al. 2015).

\section{Child Investigative Interviewing in Indonesia}

The scientifically based NICHD Protocol has not been introduced into police training programs in Indonesia. Currently, Indonesian investigators are assigned to a Children and 
Women's police unit after completing basic and general police training. Specific training is provided regarding how to investigate cases involving women and children and relevant aspects of the law, e.g., the Child Protection Law (UU No. 17, 2016) and the Domestic Violence Law (UU No. 23, 2004). Although it is generally agreed that child investigative interviewing is a complex skill (Powell et al. 2016), specialized training in this area is not currently available for Indonesian police investigators.

Police investigators at the Children and Women Unit who are mandated to conduct forensic interviews are aware of the importance of interviewing children appropriately. For example, a general guideline was disseminated as a National Police Head instruction to be used in all Children and Women units (PERKAP No. 3, 2008). This guideline emphasizes the importance of creating a child-friendly approach in interviews with children. Next to the general guideline, Indonesian police investigators are trained to use specific focused questions to obtain forensically relevant information. Specifically, asking "who," "what," "where," "when," "why," and "how" questions is recommended in the guideline of the Indonesian National Police (PERKAP No. 14, 2012). These types of directive questions are focused prompts which, according to several research studies, actually elicit less relevant information from alleged CSA victims than open-prompts (Lamb et al. 2008; Lamb et al. 2009).

At the moment, child forensic interviews are not recorded in Indonesia. When children are interviewed by police investigators, the questions asked during the interview are recorded on paper or directly typed into a computer. This existing practice (PERKAP No. 14, 2012) does not comply with evidencebased practices used elsewhere (Lamb et al. 2009; Powell et al. 2010). Video or audio recording of child interviews is advised to supplement children's court room testimony (Poole 2016), and to secure an accurate record of what was said exactly by the child and the interviewer. Although child forensic interviews by Indonesian police are currently not recorded, interview notes from the Indonesian police might provide crucial insights into existing interviewing practices in Indonesia.

\section{The Present Studies}

The goal of the current studies is to examine the quality of child investigative interviewing in Indonesia. To date, most studies examining the quality of child interviewing have been performed in Western educated industrialized rich democratic (WEIRD) societies (see Henrich et al. 2010). Non-Western countries such as Indonesia have a different culture, language, and legal system compared to most Western countries which may affect the way children are interviewed. For example, people in East Asia tend to adjust their attitude and behavior depending on situational factors such as who they are with. They often have an innate desire to please authority figures. In child interviewing contexts, children might say "yes" very often to please adults (Kanagawa et al. 2001). Reporting CSA to authorities in a non-Western, collectivistic culture is perceived as a harmful decision because of shame and the need to save face (Xie et al. 2017). Rumble et al. (2018) found that victims in Indonesia seldom disclose incidents, rarely seek support and consider CSA a private issue. Moreover, if parents or children decide to report to the police, they meet an authority and a power differential. Indonesian society has one of the largest power distance cultures (Hofstede Insights 2019). In a large power distance society, parents teach children obedience, and older people are both respected and feared (Hofstede 2011). This cultural phenomenon may interfere with best practices in police interviewing of children. Thus, developing an empathic attitude through building rapport and active listening does not come naturally to most Indonesian police officers.

Another reason to be concerned about the quality of child forensic interviews is that Indonesia is not without highly publicized cases of child sexual abuse in which poor interviews may have contributed to a miscarriage of justice. For example, the case involving the Jakarta Intercultural School (JIS) in 2015 (Hawley and Smith 2016; Millar 2018) concerns a Canadian teacher and an Indonesian teaching assistant convicted for sexually abusing kindergarten children based on a dubious account of abuse which included a magic hypnotic stone and secret hidden rooms within the JIS. They were sentenced to 11 years in prison by the Indonesian Supreme Court, which overturned their acquittal by the Higher Court. The case is highly controversial because some experts provided evidence that the children's reports are tainted by biased adults and interviewers using suggestive questions instead of open-prompts (Hawley and Smith 2016). The case raised awareness in Indonesia that children should be interviewed using evidence-based guidelines ("The Magic Stone," 2015). The current studies are a first step in examining the current quality of Indonesian forensic child interviewing. Given the cultural differences explained above, it is vital to explore the current child forensic interview practices in Indonesia.

In Study 1, we presented Indonesian police interviewers with a CSA case vignette and asked them which questions they would employ in this particular case (Appendix). In Study 2, Indonesian police files of CSA interviews were examined concerning the types of questions asked. In line with previous studies (Cyr and Lamb 2009; Lamb et al. 2009; Orbach et al. 2000; Sternberg et al. 2001a, 2001b) we predicted that in both studies, open-prompts would be rarely used and that directive, option-posing, and suggestive questions would be used with higher frequencies. 


\section{Study 1}

\section{Method}

\section{Participants}

Twenty-six police interviewers were selected by the head of the Women and Children's Unit, a special police unit within the Indonesian Police Criminal Investigation Department that handles cases involving children and women. They were employed in four police districts: East Jakarta, South Jakarta, Depok, and Tangerang (Indonesia). Participants were selected based on inclusion criteria set by the researchers: they had at least 1 year of work experience in the Women and Children's Unit and had conducted at least two forensic interviews with children during the past month. After participating in the present study, police interviewers took part in a training program in the NICHD Protocol by the first and second author.

Participants were 5 male and 21 female police investigators and their age ranged from 21 to 52 years $(M=30.08$, $S D=10.23$ ) and possessed between 1 and 34 years of work experience as a police investigator $(M=7.46, S D=8.90)$. Participants had conducted child forensic interviews, ranging from 2 to more than $100(M=35.63, S D=30.10)$. This study is part of a larger CSA research project for which ethical approval has been granted by the Ethical Review Committee (ERCPN-183_02_09_2017). The data can be accessed at the Open Science Framework (OSF) website: https://osf.io/ $\mathrm{kn} 3 \mathrm{hr} /$.

\section{Procedure}

Before the start of the NICHD Protocol training, a written survey was administered to acquire baseline data on participants' knowledge of human memory functioning and child forensic interviewing. These data will not be discussed in the present manuscript. As part of this pre-test, participants also read a case vignette of a 7-year-old girl who reported having been sexually abused by her father. Briefly, the case vignette described a scenario in which the child's mother brought the child to the police office 1 day after the alleged abuse took place. The suspected abuse occurred in the evening when the mother was away from home, and a neighbor reported that the father was home with some friends for a party that evening. After reading the case vignette, the participant was instructed to imagine that he/she was asked to conduct the forensic interview with this child and had to imagine that the child was sitting in front of him/her and that the substantive part of the interview would start. Participants were asked to write down all questions they wanted to ask to gather substantive details and relevant information of the alleged abusive event. Participants' questions were collected for coding.

\section{Data Coding}

All questions from the participants' work sheets were translated from Bahasa Indonesia to English by the first author. Subsequently, the first author coded the questions according to the different question types (open-prompts, directive, option-posing, and suggestive). The first author received training in coding questions from the second author who is an experienced NICHD Protocol trainer. The question types are derived from the NICHD utterance types (Ahern and Lamb 2017; Lamb et al. 2009). We coded a question as suggestive if the question contains information that was not disclosed from the start and also strongly communicates the desired response, for example: "I heard that someone did something bad to you, isn't it?" or "Did the perpetrator use violence, threat or seduction?" when the child had not yet mentioned violence, threat, or seduction.

\section{Interrater Reliability}

Twenty-five percent of the participants' $(n=6)$ interview questions were randomly selected for coding by the first two authors to assess interrater agreement. Cohen's $\mathrm{k}$ was .79, indicating adequate agreement between raters (Cohen 1960). Discrepancies were resolved by discussion between the two raters.

\section{Data Analysis}

First, we calculated proportions for each question type for all participants. For example: a participant who wrote down five questions in an interview plan could have the following distribution (and percentages): two open-prompts (40\%), two directives $(40 \%)$, and one option-posing (20\%). To test our predictions, a repeated measures ANOVA was conducted with type of question as within-subject variable. Post hoc Bonferroni pairwise comparisons were applied to test whether the proportions for the different question types statistically differed from each other.

\section{Results and Discussion}

On average, interviewers wrote down around five to six questions with a range from 2 to $23(M=5.88, S D=2.69,95 \%$ $C I=4.88-6.92)$. For all participants together, there were 153 questions, consisting of 80 directive questions, 37 optionposing questions, 30 suggestive questions, and only 7 openprompts. As presented in Fig. 1, the proportion of openprompts was found to be the lowest $(M=.04, S D=.11,95 \%$ $C I=.003-.09)$. Directive questions were posed the most $(M=.50, S D=.18,95 \% C I=.43-.57)$. A repeated measures ANOVA was conducted with type of question as withinsubject variable: open-prompts, directives, option-posing, 
Fig. 1 The proportion of different question types (total questions $N=153$ ) used by 26 police interviewers. $95 \%$ confidence intervals are represented in the figure by the error bars attached to each column

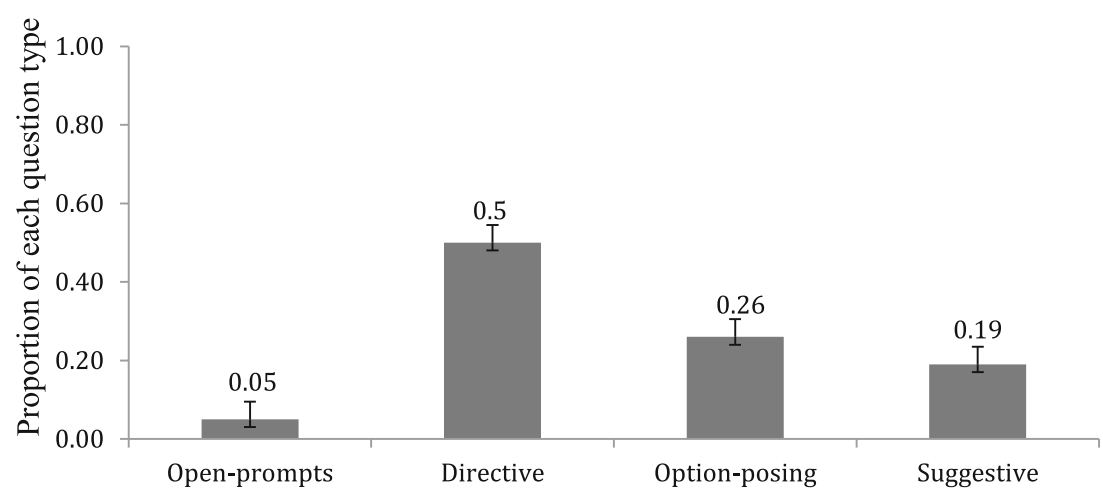

and suggestive. There was a statistically significant effect of question type, $F(3,75)=30.12, p<.001, \eta_{p}{ }^{2}=.546$, indicating that a certain question type was more likely to be asked than other types of questions. The main analysis was followed by post-hoc Bonferroni comparisons which showed that almost all question types differed significantly from each other ( $p s<.01$ ), only option-posing and suggestive questions were not statistically significant different from one another $(p=.65$, 95\% $C I=-.055-.21$; see Fig. 1).

Our findings are in line with previous studies: interviewers who have not been trained in an evidence-based child forensic interview protocol wrote down few open-prompts and used relatively more directive, option-posing, and suggestive questions (Benia et al. 2015; Cyr and Lamb 2009; Cyr et al. 2012; Lamb et al. 2009; Orbach et al. 2000; Sternberg et al. 2001a, $2001 b$ ), whereas ideally these relative proportions would be in the opposite direction. Of the 26 participants, only 6 (23\%) entered at least one open-prompt in their notes. Another notable finding was the large proportion of suggestive questions (19\%), with suggestive questions asked by 20 participants (77\%). This study provides preliminary data on how police interviewers in Indonesia may interview children who have allegedly experienced CSA. To further test our hypothesis, we conducted a second study in which we analyzed police files involving real cases of alleged CSA.

\section{Study 2}

\section{Method}

\section{Sample}

We examined 24 forensic child interview reports of alleged CSA cases from two Women and Children's Units: East Jakarta and Depok. These interview reports were part of police files provided by the local authorities for the first author's research project. The interview reports were documented in a question and answer format. There were no available video or audio recordings of the interviews. We could not randomly select the case files because there was limited access granted by the authorities. However, for cases that we could examine, we used the following inclusion criteria: the case had to concern alleged CSA victims under the age of 14 that contained an interview report in a question and answer format. We excluded case files $(n=9)$ with interview reports that only contained summaries of the interview. The interviews were conducted between 2010 and 2016 with 22 children ranging in age between 4 and 14 years $(M=10.13, S D=3.04)$; one child was a boy. Two children were interviewed twice. There are no published data on the exact number of forensic child interview reports of alleged CSA cases performed in these two Women and Children's Units. Based on unpublished statistics provided by the Head of one Women and Children's Unit where the data collection for the current study took place, on average around 78 CSA cases were handled every year between 2013 and 2017. The majority of the children (62.5\%) reported penetrative child sexual abuse. Our forensic interviews were conducted by 14 different police investigators ranging in age between 20 and 44 years with between 1 to 24 years working experience $(M=33.26, S D=7.07)$. The data can be accessed at OSF: https://osf.io/smcvx/.

\section{Procedure}

After collecting the interview reports from the police case files, the first author translated all questions stated in the report into English. Subsequently, the first author coded all questions on the basis of the NICHD utterance types (Ahern and Lamb 2017; Lamb et al. 2009). The coding procedure used was exactly the same as the one used in Study 1.

\section{Interrater Reliability}

To assess interrater agreement, $25 \%$ of the randomly selected interview reports $(n=6)$ were coded by the first two authors to assess interrater agreement. Cohen's $\mathrm{K}$ was .65 indicating substantial agreement between raters (Cohen 1960). Differences between coders were discussed. The majority of disagreements occurred between suggestive versus directive 
questions. This could be explained by the fact that one of the coders did not speak Indonesian and could not determine if the child had already mentioned specific information earlier in the interview because the entire interview report was written in the Indonesian language and we only translated the interviewer's questions.

\section{Data Analysis}

First, we calculated proportions for each question type from all interview reports. The calculation of this procedure was the same as the one used in Study 1. To test our predictions, a repeated measures ANOVA was conducted with type of question as within-subject variable. Post hoc Bonferroni pairwise comparisons were applied to examine differences between the four question types.

\section{Results and Discussion}

We first calculated the number of questions in each police file $(M=13.75, S D=2.83$, range $=9-22,95 \% C I[12.71-14.92])$. From all interview reports together, there were 330 questions, consisting of 165 option-posing questions, 144 directive questions, 8 suggestive questions, and 13 open-prompts. A repeated measures ANOVA was conducted with type of question as within-subjects factor, $F(3,69)=107.68, p<.001, \eta_{p}{ }^{2}=.824$, meaning that a specific question type was more likely to be asked than other types of questions. As can be seen in Fig. 2, open-prompts $(M=.04, S D=.05,95 \% C I[.02-.06])$ and suggestive questions $(M=.03, S D=.05,95 \% C I[.01-.05])$ were infrequently used, and option-posing $(M=.49, S D=.14,95 \%$ $C I[.43-.55])$ and directives $(M=.44, S D=.13,95 \% C I$ [.39-.50]) were asked most frequently. The results of Study 2 showed that police interviewers asked few open-prompts (only $4 \%$ of all questions asked); the majority of their questions were option-posing and directive questions (93\%). Post hoc Bonferroni pairwise comparisons showed that there were significant differences between open-prompts and directives, between open-prompts and option-posing, between directives and suggestive questions, and also between option-posing and suggestive questions (all $p \mathrm{~s}<.001$; see Fig. 2). However, the remaining pairwise comparisons did not reveal a significant difference between: (1) open-prompts and suggestive questions and (2) directive and option-posing questions (both $p$ $\mathrm{s}=1$ ). These results were in line with our prediction because Indonesian police interviewers are trained to obtain information through directive questions (the " $4 \mathrm{Ws")}$.

\section{Comparative Analysis: Study 1 Versus Study 2}

The proportional rates for each question type were compared between Study 1 (case vignette) and Study 2 (actual police files) by conducting independent samples $t$ tests. We found that the mean proportion of option-posing questions was statistically significantly higher in Study $2(49 \%, S D=.14,95 \%$ $C I[.43-.55])$ than in Study $1(29 \%, S D=.18,95 \% C I$ $[.19-.32]), t(48)=-4.97, p<.001, d=1.45$. The mean proportion of suggestive questions was statistically significantly higher in Study $1(M=.19, S D=.13,95 \% C I[.14-.24])$ than in Study $2(M=.03, S D=.05,95 \% C I[.01-.05]), t(48)=$ $5.77, p<.001, d=1.68$. No statistically significant differences were found for the proportion of open-prompts $(t(48)=.36$, $p=.72, d=.12)$ and directives $(t(48)=1.31, p=.19, d=.39)$ between the two studies. Our analyses also demonstrated that suggestive questions were more often used in Study 1 than in Study 2 .

\section{International Comparisons}

We compared the findings from Study 2 with findings from previously published studies in three countries: UK (Lamb et al. 2009), USA (Sternberg et al. 2001a, 2001b), and Canada (Cyr and Lamb 2009). In these earlier studies, NICHD Protocol interviews were compared to non-protocol interviews (Lamb et al. 2008). We conducted separate univariate ANOVAs. Specifically, we first conducted an analysis between NICHD Protocol interviews of the UK, the USA, and Canada and Indonesian interviews with the types of
Fig. 2 The relative proportion of question types found in police reports of interviews with CSA victims (total number of questions $=330) .95 \%$ confidence intervals are represented in the figure by the error bars attached to each column

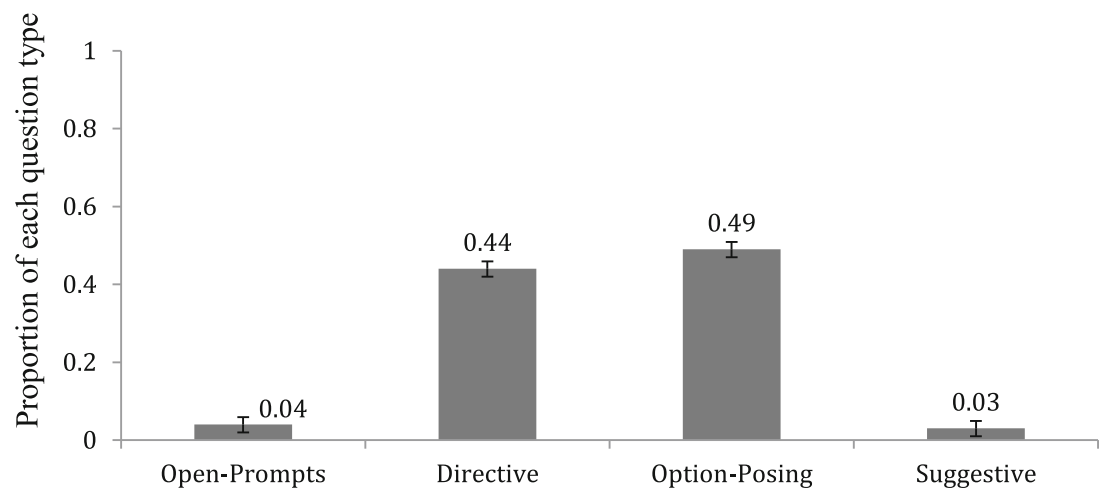


question as dependent variable. Second, we conducted analyses between non-Protocol interviews in the USA/Canada and Indonesian interviews. Afterwards, post hoc Bonferroni pairwise comparisons were conducted.

Our analyses revealed that Indonesian non-Protocol interviews contained fewer open-prompts than NICHD Protocol interviews in all comparison countries (all $p s<.001 ; 2.20 \leq$ Cohen's $d \mathrm{~s} \leq 2.77$ ). Furthermore, option-posing questions were more frequently used in the Indonesian non-Protocol interviews than in NICHD Protocol interviews from the other countries (all $p \mathrm{~s}<.001 ; 2.27 \leq$ Cohen's $d \mathrm{~s} \leq 2.77$ ). Indonesian non-Protocol interviews contained more directives than NICHD Protocol interviews in two countries: Canada $(p<.001$; Cohen's $d=1.40)$ and the USA $(p=.004$; Cohen's $d=.74$ ). For suggestive questions, there was a statistically significant difference between the Indonesian non-Protocol interviews and Canadian NICHD Protocol interviews, with fewer suggestive questions in Indonesian non-Protocol interviews ( $p=.018$; Cohen's $d=.72)$ (Fig. 3).

When comparing Indonesian non-Protocol interviews and the NICHD Protocol interviews from the UK, the USA, and Canada, our analysis replicated previous research findings that interviewers who applied the NICHD protocol use more openprompts and fewer option-posing and directives than nonprotocol interviews $(p<.001)$ (Cyr and Lamb 2009; Lamb et al. 2009; Orbach et al. 2000; Perona et al. 2005; Sternberg et al. 2001a, 2001b). In a meta-analysis, Benia et al. (2015) observed large effect sizes for the NICHD Protocol versus non-Protocol in terms of increasing the use of open-prompts and reducing the use of option-posing questions and a moderate effect size for the reduction of suggestive questions.

Subsequently, we compared non-Protocol interviews from Indonesia with non-protocol interviews from two other countries: USA and Canada. The results are presented in Fig. 4. We excluded the UK non-protocol interviews because of missing cases in the UK non-protocol interview data presented in the article. $^{1}$

Our analyses revealed that the proportion of open-prompts in Indonesian interviews was significantly lower compared to the non-protocol interviews from Canada and the USA (all $p \mathrm{~s}$ $<.05 ; 1.10 \leq$ Cohen's $d \mathrm{~s} \leq 1.12$ ). We also found that the Indonesian interviews showed the lowest proportion of suggestive questions (all $p \mathrm{~s}<.001 ; 1.09 \leq$ Cohen's $d \mathrm{~s} \leq 1.49$ ). Furthermore, Indonesian interviews revealed a significantly larger proportion of option-posing questions compared to the two countries' non-protocol interviews (all $p$ s $<.001 ; 1.01 \leq$ Cohen's $d \mathbf{s} \leq 1.19$ ). For directives, there were no significant differences between Indonesian interviews and non-protocol interviews from the USA and Canada.

\footnotetext{
${ }^{1}$ The proportion of all question types did not add up to $100 \%$ in the paper we are referring to (see Lamb et al. 2009).
}

\section{General Discussion}

The goal of our studies was to examine current forensic child interviewing practice of Indonesian police investigators in cases of alleged CSA victims. The first study focused on identifying the types of questions that Indonesian police child interviewers asked when presented with a case vignette of an alleged CSA victim. The second study aimed to assess the quality of investigative interviewing of alleged CSA victims in Jakarta, Indonesia, by analyzing interview reports included in police files. Being derived from actual police files, these data provided a good estimate of current child interviewing practices. These studies represent the first attempt to assess current police interviewing practices in Indonesia.

The most remarkable finding in both studies was that police interviewers rarely used open-prompts, but instead used mostly directive and option-posing questions. This finding indicates that police interviewers make extensive use of directed questions which ask children explicitly about their previous disclosure rather than relying on open-prompts that invite children to provide a narrative from which relevant forensic details can be collected. This is actually true of most police investigators who did not receive advanced training in child investigative interviewing (Lamb et al. 2002; Powell et al. 2016).

Quite likely, the current practice of Indonesian police interviewers is related to a lack of evidence-based investigative interviewing training. At present, no specialized training in forensic child interviewing is provided to Indonesian police investigators. We also note the unclear guidelines provided by the Head of Indonesia's National Police about how to conduct proper interviews (PERKAP No. 14, 2012). Although the regulation states, for example, that interviews should be open, conducted in a friendly and empathic manner, and should not elicit feelings of being offended (PERKAP No. 3, 2008), there are no detailed guidelines on how to implement these practices.

A substantial body of research has demonstrated that openprompts are the preferred question for investigative interviewing of children because they lead to detailed and accurate reports (Davies et al. 2000; Hershkowitz 2001; Korkman et al. 2006; Lamb et al. 2002). The consistent finding across our two studies that open-prompts were seldom used, strongly suggests that alleged CSA victims are currently not interviewed according to evidence-based principles in Indonesia. This is further demonstrated by the relatively high proportion of directives and option-posing questions which have been shown to lead to less detailed responses (Benia et al. 2015), and even worse, to less accurate and more contaminated information (Ahern and Lamb 2017; Hershkowitz 2001; Lamb et al. 2008; Perona et al. 2005; Poole 2016).

In Study 2, police investigators often started the interview with an option-posing question (e.g., "Do you know the 
Fig. 3 Comparisons of question types between Indonesian nonprotocol interviews and NICHD Protocol interviews conducted in the USA (Sternberg et al., 2001), the UK (Lamb et al. 2009), and Canada (Cyr and Lamb 2009). 95\% confidence intervals are represented in the figure by the error bars attached to each column

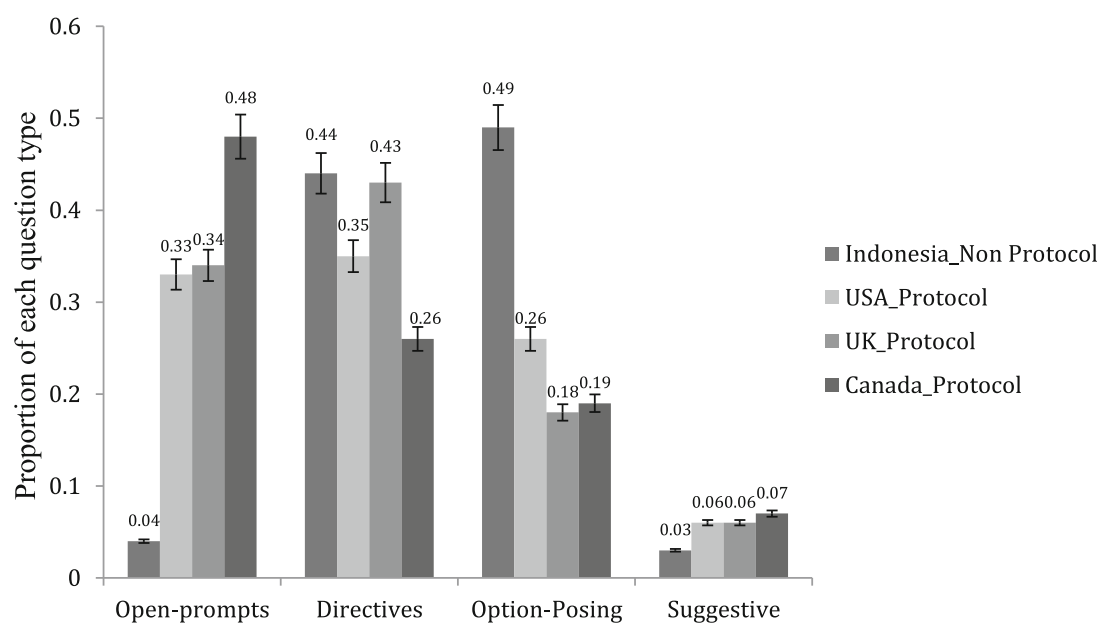

reason why you are examined and are asked to provide a statement?"). After this question, most interviewers asked directive questions concerning the suspect of the alleged CSA, the relationship with the suspect, the alleged incident, the frequency of the incident(s), and the place and time the alleged incident occurred. Option-posing questions were also used at the end of all interviews from the police files. This pattern of questioning appears to comply with guidelines and examination procedures for eyewitnesses and victims put forward by the Head of the Indonesian National Police Regulation (PERKAP No. 3, 2008). This focus on directive and optionposing questions is not in line with evidence-based guidelines on how to conduct a child forensic interview. The NICHD Protocol emphasizes that after extensive rapport building and episodic memory training, interviewers should focus on using open-prompts. Interviewers should maximize the reliance on free recall by using open-prompts and minimize the risk of eliciting erroneous information by using directives, option-posing, and suggestive questions (Lamb et al. 2002).

When we compared Study 1 and Study 2 findings, we noted that the proportion of suggestive questions was statistically significantly higher in Study 1 where participants were asked to respond to a case vignette. This finding might reflect that police interviewers to some extent planned the interview to confirm their existing pre-interview belief that the abuse actually happened. This pre-interview belief might have led to a confirmation bias (Laajasalo et al. 2018), thereby driving the use of suggestive questions. This pre-interview belief might also be the case in Study 2. However we could not capture the whole real interview process in the written documents of Study 2 and therefore, we do not know whether interviewers in these cases had received case-(ir) relevant information before the interview that might have caused pre-interview beliefs.

We also compared our data with non-protocol and NICHD Protocol interviews from other countries (Cyr and Lamb 2009; Lamb et al. 2009; Sternberg et al. 2001a, 2001b). The most important finding from the comparison with the NICHD Protocol interviews from other countries was that Indonesian interviewers used fewer open-prompts, more option-posing, and directives.

When we compared our data to non-protocol interviews from other countries, there was no difference in
Fig. 4 Comparisons of question types between Indonesian nonprotocol interviews and nonprotocol interviews conducted in the USA (Sternberg et al., 2001) and Canada (Cyr and Lamb 2009). $95 \%$ confidence intervals are represented in the figure by the error bars attached to each column

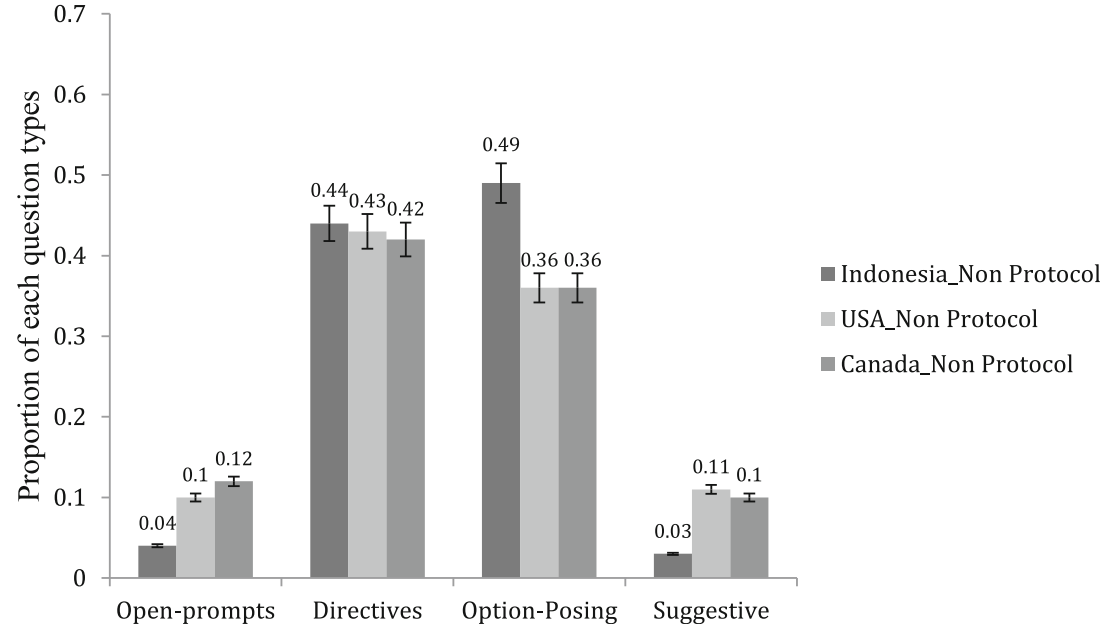


the proportion of directives. Indonesian police interviewers did, however, use fewer suggestive questions and open-prompts than their American and Canadian counterparts who did not use an interview protocol, but they more frequently employed option-posing questions. Although the finding of a relatively low proportion of suggestive questions among Indonesian interviewers is favorable, the relatively high proportion of optionposing and directive questions still runs counter to bestevidence practices in forensic child interviewing. All in all, our findings imply that current Indonesian interviewing practices need to be improved.

Several limitations of these studies need mentioning. We conducted research at the Indonesian National Police which is a highly formalized institution which requires external parties to follow strict procedures when performing scientific research. For example, we could not apply random sampling in selecting participants for Study 1 nor for the cases analyzed in Study 2. However, for Study 1, we had strict criteria for selecting police interviewers. We ensured that participants worked as police child interviewers handling CSA allegations on a regular basis.

Specifically for Study 1, we coded questions based on participants' notes as an interview plan. Nonetheless, the notes obviously did not measure participants' ability to follow-up after relevant information has been disclosed by using appropriate open-prompts to elicit additional narrative. This ability is very important in forensic interviewing (Korkman et al. 2008). Therefore, for future research, in order to evaluate interviewing skills, researchers could design an experimental study with a staged-event paradigm to provide opportunity to pose follow-up questions based on previous disclosed information (London et al. 2009; Otgaar et al. 2012).

For Study 2, we first submitted a formal letter asking access to CSA cases files from 2010 until 2016, and subsequently the Head of the Children and Women's Unit in two districts in Greater Jakarta selected and provided the cases. Our sample of interviews in Study 2 was relatively small $(N=24)$. Still, the results of Study 2 are quite promising, given the extreme proportions of optionposing and directive questions found. Another limitation is that none of the child interviews in Study 2 were recorded. We worked with the available written notes which to some extent did not capture the whole interview session. Thus, we have no way of knowing for sure that the questions described in the police reports were the actual questions asked by the police interviewers. Recording and storing all interviews conducted by police could improve current practices in Indonesian child interviewing (see also Russell 2010). This documentation could then be used to evaluate both the credibility of a child's statement and the degree to which interviewers may have contaminated these statements (Bull et al. 2009).

Our findings stress the importance of training in an evidence-based protocol for interviewing alleged CSA victims for Indonesian police interviewers. Currently, the Bahasa version of the NICHD interview protocol is available (see: http://nichdprotocol.com/bahasaIndonesia.pdf) and future research should examine the efficacy of this version in Indonesia. However, other structured interview protocols, such as the Cognitive Interview, could serve the same purpose.

Finally, our studies provide important empirical evidence for policy makers within the Indonesian National Police to promote scientifically based criminal investigative practices. Some existing guidelines for police investigators (PERKAP No. 3, 2008; PERKAP No. 14, 2012) should be revisited to encourage the police investigator to apply evidence-based interviewing practices.

The use of an evidence-based interview protocol and the recording of interviews could also not only serve the police but also professionals such as judges to render a just decision. That is, when judges have more information (e.g., verbatim transcripts of statements of children) concerning a case, they are better able to decide whether statements by a child are valid to justify sentencing.

To conclude, using two different research designs (a case vignette study and a file-based study) we found corroborative evidence that Indonesian police interviewers rarely use open-prompts and use mostly option-posing and directive questions. This shows that Indonesian police child interviewing is currently of limited quality and stresses the need to train Indonesian police child interviewers in an empirically based forensic child interview protocol.

Funding This work was supported by the Indonesian Endowment Fund (Lembaga Pengelola Dana Pendidikan - LPDP) Republic of Indonesia granted to the first author contract number 20160122105243.

\section{Compliance with Ethical Standards}

Conflict of Interest The authors declare that they have no conflict of interest.

Ethical Approval All procedures performed in studies involving human participants were in accordance with the ethical standards of the institutional and/or national research committee and with the 1964 Helsinki declaration and its later amendments or comparable ethical standards. This study is also part of a larger CSA research project for which ethical approval has been granted by the Ethical Review Committee, Faculty of Psychology and Neuroscience, Maastricht University (ERCPN183_02_09_2017).

Informed Consent Informed consent was obtained from all individual participants included in the study. 


\section{Appendix}

\section{Study 1: The Case Vignette}

\section{Original version (in Bahasa):}

Seorang anak perempuan berusia 7 tahun datang ke Unit PPA dibawa oleh ibu kandungnya sendiri. Ibunya sambil menangis mengatakan kalau anak perempuannya ini dicabuli oleh suaminya saat ini, ayah tiri dari anak perempuannya. Peristiwa pencabulan yang dilaporkan diduga terjadi kemarin malam. Ibu sambil menangis terisak menyesal karena sudah meninggalkan anak perempuannya di rumah bersama dengan suami keduanya tersebut. Ia juga dilaporkan oleh tetangganya kalau di malam itu, ada beberapa orang teman suaminya, tidak jelasnya jumlahnya, tapi kabarnya tidak lebih dari 5 orang datang ke rumah. Saat itu menurut tetangganya, suaminya dan teman-temannya tersebut seperti sedang berpesta: memasang musik dan tampak beberapa botol minuman keras.

English translation:

A 7-year-old girl was brought by her mother to you as a police investigator. The mother first sadly told to you that her girl was sexually abused by her current husband, the child's stepfather. The alleged abuse happened yesterday evening. The girl sits next to the mother, listening to all the stories being told to the police. Then the child starts to cry when she observes her mother crying loudly. The mother reports that she regrets leaving the girl at home alone with the stepfather (her current husband). She heard from her neighbor that last night, when the abused happened, her husband got a visit from his friends, around 5 adult men. During that time, her neighbor told her that her husband and his friends had a kind of a party: playing loud music. The neighbor also told her that they drank alcohol during the get-together. The mother works as a cashier in a grocery store.

Open Access This article is distributed under the terms of the Creative Commons Attribution 4.0 International License (http:// creativecommons.org/licenses/by/4.0/), which permits unrestricted use, distribution, and reproduction in any medium, provided you give appropriate credit to the original author(s) and the source, provide a link to the Creative Commons license, and indicate if changes were made.

\section{References}

Ahern EC, Lamb ME (2017) Children's reports of disclosure recipients' reactions in forensic interviews: comparing the NICHD and MoGP protocols. J Police Crim Psychol 32:85-93. https://doi.org/10.1007/ s11896-016-9205-x

Ahern EC, Hershkowitz I, Lamb ME, Blasbalg U, Winstanley A (2014) Support and reluctance in the pre-substantive phase of alleged child abuse victim investigative interviews: revised versus standard NICHD protocols. Behav Sci Law 32:762-774. https://doi.org/10. $1002 / b s 1.2149$
Ahern EC, Stolzenberg SN, Lyon TD (2015) Do prosecutors use interview instructions or build rapport with child witnesses? Behav Sci Law 33:476-492. https://doi.org/10.1002/bsl.2183

Benia LR, Hauck-Filho N, Dillenburg M, Stein LM (2015) The NICHD investigative interview protocol: a meta-analytic review. J Child Sexual Abuse 24:259-279. https://doi.org/10.1080/10538712. 2015.1006749

Borg K, Snowdon C, Hodes D (2014) Child sexual abuse: recognition and response when there is a suspicion or allegation. Paediatr Child Health 24:536-543. https://doi.org/10.1016/j.paed.2014.07.012

Bruck M, Ceci SJ (1999) The suggestibility of children's memory. Annu Rev Psychol 50:419-439. https://doi.org/10.1146/annurev.psych. 50.1.419

Bull R, Valentine T, Williamson T (2009) Handbook of psychology of investigative interviewing: current developments and future directions. Wiley - Blackwell, Chichester, UK

Cheung M, Boutte-Queen NM (2010) Assessing the relative importance of child sexual abuse interview protocol items to assist child victims in abuse disclosure. J Fam Violence 22:11-22. https://doi.org/10. 1007/s10896-009-9265-0

Cohen J (1960) A coefficient of agreement for nominal scales. Educ Psychol Meas 20:37-46. https://doi.org/10.1177/ 001316446002000104

Cross TP, Whitcomb D (2017) The practice of prosecuting child maltreatment: results of an online survey of prosecutors. Child Abuse Negl 69:20-28. https://doi.org/10.1016/j.chiabu.2017.04.007

Cross TP, De Vos E, Whitcomb D (1994) Prosecution of child sexual abuse: which cases are accepted? Child Abuse Negl 18:663-677. https://doi.org/10.1016/0145-2134(94)90016-7

Cyr M, Lamb ME (2009) Assessing the effectiveness of the NICHD investigative interview protocol when interviewing Frenchspeaking alleged victims of child sexual abuse in Quebec. Child Abuse Negl 33:257-268. https://doi.org/10.1016/j.chiabu.2008.04. 002

Cyr M, Dion J, McDuff P, Trotier-Sylvain K (2012) Transfers of skills in the context of non - suggestive investigative interviews: impact of structured interview protocol and feedback. Appl Cogn Psychol 26: 516-524. https://doi.org/10.1002/acp.2822

Daray FM, Rojas SM, Bridges AJ, Badour CL, Grendas L, Rodante D, Puppo S, Rebok F (2016) The independent effects of child sexual abuse and impulsivity on lifetime suicide attempts among female patients. Child Abuse Negl 58:91-98. https://doi.org/10.1016/j. chiabu.2016.06.011

Davies, G. M., \& Westcott, H. L. (1999). Interviewing child witnesses under the memorandum of good practice: a research review. Police research series paper. Retrieved from: http://citeseerx.ist.psu.edu/ viewdoc/download?doi=10.1.1.471.5177\&rep=rep1\&type=pdf

Davies GM, Westcott HL, Horan N (2000) The impact of questioning style on the content of investigative interviews with suspected child sexual abuse victims. Psychol Crime Law 6:81-97. https://doi.org/ 10.1080/10683160008410834

Fisher RP, Geiselman RE (1992) Memory-enhancing techniques for investigative interviewing: the cognitive interview. Charles $\mathrm{C}$ Thomas Publisher, Springfield, England

Gagnon K, Cyr M (2017) Sexual abuse and pre-schoolers: forensic details in regard of questions types. Child Abuse Negl 67:109-118. https:// doi.org/10.1016/j.chiabu.2017.02.022

Hawley, S., \& Smith, S. (2016). Calls for case into child sexual abuse scandal at prestigious Jakarta school to be reopened. Retrieved from: https://www.abc.net.au/news/2016-06-21/jakarta-school-sexabuse-scandal-calls-for-reopening/7517466

Henrich J, Heine SJ, Norenzayan A (2010) The weirdest people in the world? Behav Brain Sci 33:61-83. https://doi.org/10.1017/ S0140525X0999152X 
Herman S, Freitas TR (2010) Error rates in forensic child sexual abuse evaluations. Psychol Injury Law 3:133-147. https://doi.org/10. 1007/s12207-010-9073-0

Hershkowitz I (2001) Children's responses to open-ended utterances in investigative interviews. Leg Criminol Psychol 6:49-63. https://doi. org/10.1348/135532501168190

Hershkowitz I, Orbach Y, Lamb ME, Sternberg KJ, Horowitz D, Hovav M (1998) Visiting the scene of the crime: effects on children's recall of alleged abuse. Leg Criminol Psychol 3:195-207. https://doi.org/ 10.1111/j.2044-8333.1998.tb00361.x

Hershkowitz I, Lamb ME, Katz C (2014) Allegation rates in forensic child abuse investigations: comparing the revised and standard NICHD protocols. Psychol Public Policy Law 20:336-334. https:// doi.org/10.1037/a0037391

Hofstede G (2011) Dimensionalizing cultures: the Hofstede model in context. Online Readings in Psychology and Culture 2. https://doi. org/10.9707/2307-0919.1014

Hofstede Insight. (2019). Country comparison: Indonesia. Retrieved from: https://www.hofstede-insights.com/country-comparison/ indonesia/

Kanagawa C, Cross SE, Markus HR (2001) Who am I? The cultural psychology of the conceptual self. Personal Soc Psychol Bull 27: 90-103. https://doi.org/10.1177/0146167201271008

Korkman J, Santtila P, Sandnabba K (2006) Dynamics of verbal interaction between interviewer and child in interviews with alleged victims of child sexual abuse. Scand J Psychol 47:109-119. https://doi. $\operatorname{org} / 10.1111 / \mathrm{j} .1467-9450.2006 .00498 . x$

Korkman J, Santtila P, Westeraker M, Sandnabba NK (2008) Interviewing techniques and follow-up questions in child sexual abuse interviews. Eur J Dev Psychol 5:108-128. https://doi.org/10. 1080/17405620701210460

La Rooy D, Brubacher SP, Aromäki-Stratos A, Cyr M, Hershkowitz I, Korkman J, Stewart H (2015) The NICHD protocol: a review of an internationally-used evidence-based tool for training child forensic interviewers. J Criminol Res Policy Pract 1:76-89. https://doi.org/ 10.1108/JCRPP-01-2015-0001

Laajasalo T, Korkman J, Pakkanen T, Oksanen M, Tuulikki L, Peltomaa E, Aronen ET (2018) Applying a research-based assessment model to child sexual abuse investigations: model and case descriptions of an expert center. J Forensic Psychol Res Pract 2:177-197. https:// doi.org/10.1080/24732850.2018.1449496

Lamb ME, Sternberg KJ, Esplin PW (2000) Effects of age and delay on the amount of information provided by alleged sex abuse victims in investigative interviews. Child Dev 71:1586-1596. https://doi.org/ 10.1111/1467-8624.00250

Lamb ME, Sternberg KJ, Orbach Y, Hershkowitz I, Horowitz D, Esplin PW (2002) The effects of intensive training and ongoing supervision on the quality of investigative interviews with alleged sex abuse victims. Appl Dev Sci 6:114-125. https://doi.org/10.1207/ S1532480XADS0603 2

Lamb ME, Sternberg KJ, Orbach Y, Esplin PW, Stewart H, Mitchell S (2003) Age differences in young children's responses to open-ended invitations in the course of forensic interviews. J Consult Clin Psychol 71:926-934. https://doi.org/10.1037/0022-006X.71.5.926

Lamb ME, Orbach Y, Hershkowitz I, Esplin PW, Horowitz D (2007) A structured forensic interview protocol improves the quality and informativeness of investigative interviews with children: a review of research using the NICHD investigative interview protocol. Child Abuse Negl 31:1201-1231. https://doi.org/10.1016/j.chiabu.2007. 03.021

Lamb ME, Hershkowitz I, Orbach Y, Esplin PW (2008) Tell me what happened: structured investigative interviews of child victims and witnesses. Wiley, Chichester, UK

Lamb ME, Orbach Y, Sternberg KJ, Aldridge J, Pearson S, Steward HL, Esplin PW, Bowler L (2009) Use of a structured investigative protocol enhances the quality of investigative interviews with alleged victims of child sexual abuse in Britain. Appl Cogn Psychol 23:449 467. https://doi.org/10.1002/acp.1489

London K, Bruck M, Melnyk L (2009) Post-event information affects children's autobiographical memory after one year. Law Hum Behav 33:344-355. https://doi.org/10.1007/s10979-008-9147-7

Lyon, T. D. (2005). Ten step investigative interview. Retrieved from: http://works.bepress.com/thomaslyon/5

Millar, P. (2018). Why Indonesian activists are defending school employees jailed for child sexual abuse. Retrieved from: http://seaglobe.com/neil-bantleman/

Orbach Y, Hershkowitz I, Lamb ME, Sternberg KJ, Esplin PW, Horowitz D (2000) Assessing the value of structured protocols for forensic interviews of alleged child abuse victims. Child Abuse Negl 24: 733-752. https://doi.org/10.1016/S0145-2134(00)00137-X

Otgaar H, Horselenberg R, van Kampen R, Lalleman K (2012) Clothed and unclothed human figure drawings lead to more correct and incorrect reports of touch in children. Psychol Crime Law 18:641653. https://doi.org/10.1080/1068316X.2010.532129

Otgaar H, de Ruiter C, Howe ML, Hoetmer L, van Reekum P (2017) A case concerning children's false memories of abuse: recommendations regarding expert witness work. Psychiatry Psychol Law 24: 365-378. https://doi.org/10.1080/13218719.2016.1230924

Otgaar H, Chan JCK, Calado B, La Rooy D (2018a) Immediate interviewing increases children's suggestibility in the short term, but not in the long term. Legal and Criminal Psychology 24:1-17. https://doi.org/10.1111/lcrp.12137

Otgaar H, Howe ML, Merckelbach H, Muris P (2018b) Who is the better eyewitness? Sometimes adults but at other times children. Curr Dir Psychol Sci 27:378-385. https://doi.org/10.1177/ 0963721418770998

PERKAP: Peraturan Kepala Kepolisian Negara Republik Indonesia (2008) tentang Pembentukan Ruang Pelayanan Khusus dan Tata Cara Pemeriksaan Saksi dan/atau Korban Tindak Pidana Regulation of Head of Republic of Indonesia National Police of the Special Service Unit and Procedures in Examining Eyewitness and Victims of Criminal Act. 3.

PERKAP: Peraturan Kepala Kepolisian Negara Republik Indonesia (2012) tentang Manajemen Penyidikan Tindak Pindana - The Management of Criminal Investigation. 14.

Perona AR, Bottoms BL, Sorenson E (2005) Research-based guidelines for child forensic interviews. J Aggress Maltreat Trauma 12:81-130. https://doi.org/10.1001/jamapediatrics.2014.3357

Pichler AS, Sharman SJ, Powell M, Westera N, Goodman-Delahunty J (2019) Association between interview quality and child sexual abuse trial outcome. J Fam Violence 34:1-9. https://doi.org/10. 1007/s10896-019-00051-5

Pipe ME, Orbach Y, Lamb ME, Abbott CB, Stewart H (2013) Do case outcomes change when investigative interviewing practices change? Psychol Public Policy Law 19:179-190. https://doi.org/10.1037/ a0030312

Poole DA (2016) The science of interviewing children. In: Poole DA (ed) Interviewing children: The science of conversation in forensic contexts (pp.7-27). US: American Psychological Association, Washington, DC. https://doi.org/10.1037/14941-002

Powell M, Wright R, Clark S (2010) Improving the competency of police officers in conducting investigative interviews with children. Police Pract Res 11:211-226. https://doi.org/10.1080/ 15614260902830070

Powell MB, Guadagno B, Benson M (2016) Improving child investigative interviewer performance through computer-based learning activities. Polic Soc 26:365-374. https://doi.org/10.1080/10439463. 2014.942850

Undang - Undang (UU) No. 23 tentang Penghapusan Kekerasan Dalam Rumah Tangga (The Domestic Violence Eradication Act) Republik Indonesia. (2004) 
Undang - Undang (UU) No. 17 tentang Perubahan Kedua atas Undang Undang Nomor 23 tahun 2002 tentang Perlindungan Anak (The Second Revision of Child Protection Act) Republik Indonesia. (2016)

Rumble L, Febrianto RF, Larasati MN, Hamilton C, Mathews B, Dunne MP (2018) Childhood sexual violence in Indonesia: a systematic review. Trauma Violence Abuse 19:1-16. https://doi.org/10.1177/ 1524838018767932

Russell, A. (2010). Documentation and assessment of children's forensic interview statement. Widener Law Review, 16, 305-333. Retrieved from: https://www.gundersenhealth.org/app/files/public/2776/ NCPTC-Documentation-and-Assessment-of-Childrens-ForensicInterview-Statements.pdf

Saywitz KJ, Larson RP, Hobbs SD, Wells CR (2015) Developing rapport with children in forensic interviews: systematic review of experimental research. Behav Sci Law 33:372-389. https://doi.org/10. $1002 / b s 1.2186$

Sternberg KJ, Lamb ME, Hershkowitz I, Esplin PW, Redlich A, Sunshine N (1996) The relation between investigative utterance types and the informativeness of child witnesses. J Appl Dev Psychol 17:439451. https://doi.org/10.1016/S0193-3973(96)90036-2

Sternberg KJ, Lamb ME, Davies GM, Westcott HL (2001a) The memorandum of good practice: theory versus application. Child Abuse Negl 25:669-681. https://doi.org/10.1016/S0145-2134(01)00232-0

Sternberg KJ, Lamb ME, Orbach Y, Esplin PW, Mitchell S (2001b) Use of a structured investigative protocol enhances young children's responses to free-recall prompts in the course of forensic interviews. J Appl Psychol 86:997-1005. https://doi.org/10.1037/0021-9010. 86.5.997

Stoltenborgh M, van IJzendoorn MH, Euser EM, Bakermans-Kranenburg MJ (2011) A global perspective on child sexual abuse: meta-analysis of prevalence around the world. Child Maltreatment 16:79-101. https://doi.org/10.1177/1077559511403920

The magic stone -30 things you should know about the JIS case. (2015). Retrieved from: https://www.wowshack.com/the-magic-stone-30things-you-should-know-about-the-jis-case/
United Nations International Children Emergency Fund (UNICEF). (2004). The convention on the rights of the child (UNCRC). Retrieved from: https://downloads.unicef.org.uk/wp-content/ uploads/2010/05/UNCRC_united_nations_convention_on_the rights of the child.p $\overline{d f}$ ? ga $=2.476 \overline{0} 9573.335 \overline{2} 71616$. $153907 \overline{3} 97 \overline{6}-386802020.1539073976$

Widom CS, Massey C (2015) A prospective examination of whether childhood sexual abuse predicts subsequent sexual offending. JAMA Pediatr 169:1-7. https://doi.org/10.1001/jamapediatrics. 2014.3357

Wood JM, Garven S (2000) How sexual abuse interviews go astray: implications for prosecutors, police, and child protective services. Child Maltreatment 5:109-119. https://doi.org/10.1177/ 1077559500005002003

Xie QW, Sun X, Chen M, Qiao DP, Chan KL (2017) What prevents Chinese parents from reporting possible cases of child sexual abuse to authority? A holistic-interactionistic approach. Child Abuse Negl 64:19-31. https://doi.org/10.1016/j.chiabu.2016.12.006

Yuille JC, Cooper BS, Hervé HF (2009) The step wise guidelines for child interviews: the new generation. In M. Casonato \& F. Pfafflin (Eds.), Handbook of pedosexuality and forensic science Retrieved from: https://theforensicpractice.com/pdf/Step-Wise\% 20 guidelines $\% 20$ for $\% 20$ child $\% 20$ interviews $\% 20-\% 20$ the $\%$ 20next\%20generation\%202009.pdf

Yuille JC, Hunter R, Joffe R, Zaparniuk J (1993) Interviewing children in sexual abuse cases. In: Goodman GS, Bottoms BL (eds) Child victims, child witnesses: understanding and improving testimony. Guilford Press, New York, NY, US, pp 95-115

Publisher's Note Springer Nature remains neutral with regard to jurisdictional claims in published maps and institutional affiliations. 